\title{
Bi-Lateral Changes to Hippocampal Cholesterol Levels During Epileptogenesis and in Chronic Epilepsy Following Focal-Onset Status Epilepticus in Mice
}

\author{
Steve Meaney \\ Technological University Dublin, steve.meaney@tudublin.ie \\ Maura Heverin \\ Royal College of Surgeons in Ireland \\ Tobias Engel \\ Royal College of Surgeons in Ireland
}

See next page for additional authors

Follow this and additional works at: https://arrow.tudublin.ie/scschbioart

Part of the Nervous System Diseases Commons

Recommended Citation

10.1016/j.brainres.2012.08.018

This Article is brought to you for free and open access by the School of Biological Sciences at ARROW@TU Dublin. It has been accepted for inclusion in Articles by an authorized administrator of ARROW@TU Dublin. For more information, please contact arrow.admin@tudublin.ie, aisling.coyne@tudublin.ie, gerard.connolly@tudublin.ie.

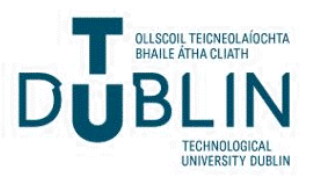




\section{Authors}

Steve Meaney, Maura Heverin, Tobias Engel, Eva Jimenez-Mateosa, Reza Al-Aaudia, and David Henshall 
Dublin Institute of Technology

ARROW@DIT

Articles

2012

Bi-lateral changes to hippocampal cholesterol levels during epileptogenesis and in chronic epilepsy following focal-onset status epilepticus in mice

Steve Meaney

Maura Heverin

Tobias Engel

Eva Jimenez-Mateosa

Reza Al-Aaudia

See next page for additional authors

Follow this and additional works at: http:/ / arrow.dit.ie/despart

Part of the Nervous System Diseases Commons

This Article is brought to you for free and open access by ARROW@DIT. It has been accepted for inclusion in Articles by an authorized administrator of ARROW@DIT. For more information, please contact

yvonne.desmond@dit.ie, arrow.admin@dit.ie. 
Authors

Steve Meaney, Maura Heverin, Tobias Engel, Eva Jimenez-Mateosa, Reza Al-Aaudia, and David Henshall 
Bi-lateral changes to hippocampal cholesterol levels during epileptogenesis and in chronic epilepsy following focal-onset status epilepticus in mice

Maura Heverina, b, 1, Tobias Engela, Steve Meaneyc, Eva M. Jimenez-Mateosa, Reza AlSaudia, David C. Henshalla

a Department of Physiology and Medical Physics, Royal College of Surgeons in Ireland, 123 St. Stephen's Green, Dublin 2, Ireland

b Division of Clinical Chemistry, Department of Laboratory Medicine, Karolinska Institute, Karolinska University Hospital Huddinge, Sweden

c School of Biological Sciences, Dublin Institute of Technology, Kevin Street, Dublin, Ireland 


\begin{abstract}
Brain cholesterol homeostasis has been shown to be disrupted in neurodegenerative conditions such as Alzheimer's and Huntington's diseases. Investigations in animal models of seizure-induced brain injury suggest that brain cholesterol levels are altered by prolonged seizures (status epilepticus) and are a feature of the pathophysiology of temporal lobe epilepsy. The present study measured hippocampal sterol levels in a model of unilateral hippocampal injury triggered by focal-onset status epilepticus, and in chronically epileptic mice. Status epilepticus was induced by intra-amygdala microinjection of kainic acid and ipsilateral and contralateral hippocampus analyzed. No significant changes were found for ipsilateral or contralateral hippocampal levels of desmosterol or lathosterol at any time after SE as measured by gas chromatographymass spectrometry. 24S-hydroxycholesterol and cholesterol levels were unchanged up to $24 \mathrm{~h}$ after status epilepticus but were decreased in the ipsilateral hippocampus during early epileptogenesis and in chronically epileptic mice. Levels of cholesterol were also reduced in the contralateral hippocampus during epileptogenesis and in chronic epileptic mice. Treatment of mice with the anti-inflammatory cholesterol synthesis inhibitor lovastatin did not alter seizures during status epilepticus or seizure-induced neuronal death. Thus, changes to hippocampal cholesterol homeostasis predominantly begin during epileptogenesis, occur bi-laterally even when the initial precipitating injury is unilateral, and continue into the chronic epileptic period.
\end{abstract}




\section{Introduction}

Cholesterol is a key component of the brain. This is underscored by the fact that the brain is the most cholesterol-rich organ in the body and contains $25-30 \%$ of total body cholesterol content. It is a major structural component of plasma membranes and myelin, where it is critical for rapid conduction of nerve transmission. Cholesterol has also been directly implicated in various neuronal functions, including synaptogenesis and neurotransmitter release (Mauch et al., 2001 and Thiele et al., 2000). Indirectly it has a general influence on cerebral biochemistry via conversion into bioactive steroids such as neurosteroids and oxysterols. A noteworthy feature of brain cholesterol is that the brain meets its cholesterol requirements entirely by local synthesis, as cholesterol containing lipoproteins from the periphery are excluded from the brain by the bloodbrain barrier (Bjorkhem and Meaney, 2004).

Although the average rate of cholesterol synthesis in the adult brain is relatively low there is a need to remove excess cholesterol from the brain (Bjorkhem et al., 1998). One mechanism for this involves cholesterol carried in apolipoprotein E (APOE)-containing lipoproteins which pass through the cerebrospinal fluid and eventually reach the circulation where they presumably integrate into peripheral lipoprotein metabolism ( Pitas et al., 1987b). The second, more quantitatively important process is based on conversion of cholesterol into the oxysterol 24S-hydroxycholesterol (24S-OHC). In contrast to cholesterol, 24S-0HC can pass the blood-brain barrier and directly enter the general circulation. As $24 \mathrm{~S}-\mathrm{OHC}$ is ultimately cleared by the liver, this system effectively acts as a brain-initiated pathway of reverse cholesterol transport ( Lund et al., 1999). The cytochrome P450 enzyme, cholesterol 24-hydroxylase (CYP46A1) mediates this transformation and is therefore a key determinant of the rate of cholesterol removal from the brain (Lund et al., 2003). In humans, CYP46A1 is exclusively expressed in the brain and under normal conditions the enzyme protein is detected only in neurons, in particular in the pyramidal neurons and interneurons of the hippocampus ( Lund et al., 1999 and Ramirez et al., 2008).

Seizures are a co-morbidity in a variety of diseases associated with pathologic cholesterol metabolism. Whether epilepsy, which is characterized by recurrent spontaneous seizures, is also associated with alterations of cholesterol metabolism and whether these are causally important for either seizure-induced neuronal death or the pathogenesis of hippocampal sclerosis, the most common pathologic lesion in temporal lobe epilepsy (Engel et al., 2011), is unknown. Previous studies reported an increase in cholesterol and certain oxysterols in the hippocampus of rats following kainic acid (KA)induced seizures (Ong et al., 2003). We recently reported that brief seizures in mice increase the expression of StAR-related lipid transfer domain containing 4 (Stard4), which can bind cholesterol and is involved in intracellular cholesterol transport ( Hatazaki et al., 2007). A number of studies have also explored the effects of statins on seizure-induced neuronal death ( He et al., 2006, Lee et al., 2008 and Xie et al., 2011). Statins competitively inhibit the rate-limiting enzyme in cholesterol synthesis, 3hydroxy-3-methylglutaryl coenzyme-A reductase (HMGCR), and are a commonly prescribed as cholesterol-lowering agent. Atorvastatin has been reported to reduce hippocampal neuronal death in rodent models of excitotoxicity in vivo ( Lee et al., 2008 and Piermartiri et al., 2009) and lovastatin treatment of rats reduced sterol levels and increased neuronal survival after status epilepticus ( He et al., 2006). 
The previous reports of a protective effect of statins in rat models of seizure-induced damage prompted us to investigate if this was also the case in a model of status epilepticus in mice in which seizures are focally-evoked by intra-amygdala microinjection of KA ( Araki et al., 2002 and Mouri et al., 2008). The results of this led us to characterize in detail the immediate and long-term effects on brain sterol homeostasis after status epilepticus in this model.

\section{Results}

2.1. Intra-amygdala KA-induced status epilepticus results in unilateral hippocampal pathology and spontaneous recurrent seizures

Focal-onset status epilepticus in mice was produced by intra-amygdala microinjection of KA. All mice developed seizures within a few minutes after KA injection and displayed typical behavioral changes including initial immobility, tail extension (Straub-tail) and continuing to clonus, head bobbing and rearing and falling, and occasionally tonic-clonic seizures with loss of posture and jumping. Cortical EEG recordings during seizures detected high amplitude and high frequency discharges ( Fig. 1B). Animals were administered lorazepam to curtail seizures and reduce morbidity and mortality $40 \mathrm{~min}$ after KA. Examination of tissue sections from mice $24 \mathrm{~h}$ after status epilepticus revealed neuronal cell death mainly in the CA3 region of the ipsilateral hippocampus ( Fig. 1C). Neuronal death was not observed in the contralateral hippocampus ( Fig. 1C).

Consistent with previous reports (Mouri et al., 2008), intermittent video and EEG monitoring of mice after status epilepticus detected the emergence of spontaneous (i.e. epileptic) after KA injection ( Fig. 1D and E). In tissue sections from epileptic mice 14 day after status epilepticus, the hippocampus displayed neuronal loss within the ipsilateral CA3 subfield ( Fig. 1F). The contralateral hippocampus appeared normal, without any obvious changes in cell density ( Fig. 1F). To determine whether there was any ongoing cell death in epileptic mice, sections from mice 14 days after status epilepticus were stained for DNA fragmentation characteristic of seizure-induced neuronal death using terminal deoxynucleotidyl dUTP nick end labeling (TUNEL) and the neuronal marker (NeuN). No TUNEL-positive cells were detected in the CA3 region of the ipsilateral hippocampus from mice 14 days after status epilepticus ( Fig. 1G).

\subsection{Lovastatin treatment does not prevent hippocampal damage caused by intra- amygdala KA-induced status epilepticus}

Statins have been reported to have potent neuroprotective effects against seizureinduced neuronal death in rats (Lee et al., 2008, Ohyama et al., 2006 and Rangel et al., 2005). To test if lovastatin treatment has such an effect in the present model, mice were treated for three consecutive days with lovastatin using a dose previously shown to lower brain cholesterol in animal models (Lee et al., 2008). On the fourth day, mice received lovastatin before and after being subjected to KA-induced status epilepticus, and then received lovastatin again on the two subsequent days. Brains were collected 72 $\mathrm{h}$ after status epilepticus. Because previous studies have reported that statins can alter seizure severity ( Lee et al., 2008), the EEG was recorded for 40 min after KA injection until administration of the anticonvulsant lorazepam and quantified to define the durations of injury-causing electrographic seizures.

Lovastatin treatment had no observable effect on the duration or severity of electrographic seizures during status epilepticus induced by intra-amygdala KA ( Fig. 2A 
and B). We next explored whether lovastatin treatment had any effects on seizureinduced neuronal death. Analysis of tissue sections from the dorsal and ventral hippocampus of mice subject to status epilepticus and given injections of vehicle revealed typical ipsilateral CA3 subfield damage ( Fig. 2C and D). Seizure-induced neuronal death was similar in mice treated daily with lovastatin before and after status epilepticus in both dorsal and ventral hippocampus ( Fig. 2C and D).

2.3. Sterol level changes over time after status epilepticus in the ipsilateral hippocampus Next we measured cholesterol level changes in the ipsilateral hippocampus after status epilepticus. Our goal was to assess cholesterol homeostasis during the period of major seizure-induced damage, the period prior to the emergence of spontaneous seizures, and in mice with recurring epileptic seizures. Thus, hippocampus from mice was analyzed at 4 and $24 \mathrm{~h}$ after status epilepticus (which corresponds to the period of major neurodegeneration-see Fig. 1C), at $48 \mathrm{~h}$ (which corresponds to the time immediately prior to first spontaneous seizures, otherwise known as the latent period) and at 14th day (when mice have daily spontaneous seizures (Fig. 1D and E) (Mouri et al., 2008)). Time-matched groups of vehicle-injected non-seizure mice were included at each time point.

Gas chromatographic-mass spectrometric measurements of ipsilateral hippocampal samples determined that levels of the cholesterol precursors lathosterol and desmosterol, the cholesterol metabolite 24-OHC, as well as cholesterol, were not different from controls at 4 or $24 \mathrm{~h}$ after status epilepticus ( Fig. 3A-C and E). The cholesterol metabolite 27-hydroxycholesterol (27-OHC) was lower at $4 \mathrm{~h}$ in seizure mice ( Fig. 3D).

In samples obtained during the pre-epileptic period after status epilepticus ( $48 \mathrm{~h}$ ), levels of 24-OHC and cholesterol were significantly lower in KA-treated mice compared to controls ( Fig. 3C and E). Levels of lathosterol, desmosterol and 27-OHC were similar between groups. In samples taken $336 \mathrm{~h}$ (14 days) after status epilepticus, when mice experience daily epileptic seizures, levels of the cholesterol metabolites 24-OHC and 27OHC, and cholesterol were significantly lower than controls ( Fig. 3C-E), whereas levels of lathosterol and desmosterol remained unchanged ( Fig. 3A and B).

\subsection{Sterol level changes in the contralateral hippocampus after status epilepticus}

Because the present model features a unilateral injury to the hippocampus, we next asked whether changes occurred in the contralateral hippocampus, which is not a site of neuron loss in the model (Fig. 1C and Mouri et al. (2008)). Remarkably, changes to sterol levels were also observed in the contralateral hippocampus (Fig. 4). Four hours after status epilepticus, all sterol levels were unchanged in the contralateral hippocampus (Fig. 4A-E). At $24 \mathrm{~h}$, levels of 24-OHC were significantly decreased in KA-treated mice ( Fig. 4C), and at $48 \mathrm{~h}$ levels of 24-OHC, 27-OHC and cholesterol were all lower in the seizure animals ( Fig. 4C-E). Contralateral hippocampal levels of 24-OHC, 27-OHC and cholesterol were all lower than control in epileptic mice ( Fig. 4C-E).

\section{Discussion}

Previous studies have suggested that the statin class of cholesterol synthesis inhibitors are capable of protecting against hippocampal injury in models of seizure-induced neuronal death (He et al., 2006, Lee et al., 2008, Piermartiri et al., 2009, Rangel et al., 
2005 and Xie et al., 2011). Statin treatment has been shown to reduce cell death in the hippocampus in mice with quinolinic acid-induced seizures and in rats with pilocarpine and KA-induced seizures. Some of these studies provide evidence to suggest statins may be neuroprotective by limiting glutamate-mediated neurotoxicity or by suppressing the inflammatory response (Lee et al., 2008, Piermartiri et al., 2009 and Xie et al., 2011). Others suggest that statins are neuroprotective via reduction in the rate of formation of neurotoxic oxysterols in the brain, due to the blockade of cholesterol synthesis and reduction of substrate supply (He et al., 2006). In the present study we treated mice before and after status epilepticus triggered by intra-amygdala KA with lovastatin, a prototypical statin ( He et al., 2006). In contrast to other reports ( He et al., 2006 and Rangel et al., 2005), we observed no protective effects of lovastatin against seizureinduced neuronal death. Thus, statins are not broadly protective against neuronal death caused by prolonged seizures.

In previous studies, a protective effect of statins was matched by biochemical changes in the rat brain and the present study also sought to determine if the absence of a protective effect was recapitulated in brain sterol biochemistry. Changes in sterol levels in the hippocampus were detected following status epilepticus induced by intraamygdala KA in mice. However, in contrast to expectations, observed changes were invariably a decrease rather than an increase in sterols both in the immediate period after status epilepticus, during the pre-epileptic phase, and in chronically epileptic mice. In addition, our data also suggest that the hippocampus may respond bilaterally to focal damage, at least with regard to sterol homeostasis-changes in sterol content were very similar between the contra- and ipsi-lateral sides after status epilepticus in this model (Fig. 3 and Fig. 4). Thus, the present study shows that the main changes in brain cholesterol after status epilepticus occur bi-laterally and during the period of epileptogenesis and chronic epilepsy, rather than as the immediate wake of KA-induced seizure-damage.

The present findings, particularly given their bi-lateral nature, suggest sterol changes are not a simple result of neuron loss or astrogliosis because both differ greatly between ipsilateral and contralateral sides in the model (Mouri et al., 2008). Instead, our data support the changes due to alterations in gene expression and/or lipoprotein secretion. A reduction in the $24 \mathrm{~S}-\mathrm{OHC}$ level was a consistent and pronounced observation. Cholesterol is removed from the brain by two known pathways: formation of 24Shydroxycholesterol and efflux across the blood-brain barrier and removal of lipoprotein bound cholesterol via the cerebrospinal fluid (Bjorkhem et al., 1998 and Pitas et al., 1987a). Under conditions of chronic neurodegeneration the capacity for the formation of $24 \mathrm{~S}-\mathrm{OHC}$ is expected to be compromised, due to a decrease in the number of neurons while the flux through lipoprotein-dependent pathways would be expected to increase (Papassotiropoulos et al., 2000). Damage from status epilepticus, coupled with subsequent regular seizures, may recapitulate this situation in an acute time frame and blunt the capacity of the hippocampus to engage either 24S-OHC and/or lipoproteindependent mechanisms for mobilization of cholesterol. Another cholesterol oxidation product, 27-OHC was also significantly reduced after status epilepticus. However, normal levels of this oxysterol are relatively very low in the hippocampus in comparison to $24 \mathrm{~S}-\mathrm{OHC}$. We have previously shown that a substantial part of this cerebral 27-OHC originates from outside the brain ( Heverin et al., 2005). While we have evidence to suggest that it further metabolized to an acid which then fluxes out of the brain we do 
not know the function of 27-OHC in the brain (Meaney et al., 2007). In the present model, the decreased levels suggest a reduced uptake from the circulation by the brain or an increased metabolism in response to seizure-induced injury.

Our results contrast previous studies using rat models of KA-induced status epilepticus where large increases in both cholesterol and oxysterol content of the injured hippocampus were reported ( He et al., 2006 and Ong et al., 2003). In those studies, the authors suggested that this was a consequence of increased cholesterol synthesis, providing a rationale for the use of cholesterol synthesis inhibitors as therapeutic agents. Subsequent studies from this group have reported that the expression of cholesterol synthetic genes was decreased in this model (Kim et al., 2010) suggesting that increased synthesis is unlikely to be the cause of this large increase. These studies contrast with our study in that cholesterol levels were unaffected until $48 \mathrm{~h}$ after status epilepticus despite major cell death being detectable at $24 \mathrm{~h}$. We found that cholesterol-related levels of lathosterol and desmosterol, which are established biochemical markers of the rate of cholesterol synthesis ( Bjorkhem et al., 1987 and Kempen et al., 1988), were not changed in the KA treated animals which suggests that cholesterol synthesis is not decreased in our model. The use of different species and techniques for triggering status epilepticus preclude direct comparisons and in our study each time point had matched controls treated with vehicle along with distinct pathophysiology between ipsilateral and contralateral hippocampi.

An unexpected finding was that changes were as pronounced in the undamaged, contralateral hippocampus as they were in the damaged ipsilateral hippocampus. Again, changes followed the major period of cell death, occurring during the pre-epileptic period and in the chronic epileptic mice. Contralateral hippocampal pathology has been reported in other mouse models of KA-induced status epilepticus ( Arabadzisz et al., 2005 and Pernot et al., 2011) but is more surprising in the present model because of the lack of neuronal death or astrogliosis (present study and Mouri et al. (2008)).

Inflammatory changes such as microgliosis and astrogliosis do occur in the contralateral hippocampus in the initial phase of epileptogenesis ( Pernot et al., 2011) and in another model, neurochemical changes such as increased neuropeptide-Y were evident later in the latent and chronic phases in the contralateral hippocampus (Arabadzisz et al., 2005). We do not know the mechanism underlying the observed bilateral changes in hippocampal sterols. It has been reported that damage to the nervous system results in the upregulation of apolipoproteins $\mathrm{D}$ and $\mathrm{E}$ (ApoD and ApoE, respectively) which are believed to be involved in the recycling of sterols liberated as a consequence of cellular degeneration. Indeed, both ApoE and ApoD have been reported to undergo timedependent changes following various forms of hippocampal injury, including excitotoxicity ( Montpied et al., 1999). It is thus possible that the observed changes remote to the injection site are a consequence of altered lipoprotein content in the brain extracellular fluid and/or altered sterol transport proteins. A direct effect of spontaneous seizures is also possible.

In summary, the present study characterizes the hippocampal sterol response to focalonset status epilepticus in a mouse model of unilateral hippocampal injury and recurrent spontaneous seizures. We report bi-lateral sterol changes, despite the seizure injury to the brain being unilateral, and find this occurs during the pre-epileptic period and in chronic epilepsy rather than during the period of major neuronal death. We also 
report lovastatin does not protect against seizure-induced neuronal death. Thus, changes to brain cholesterol balance are a feature of the epileptogenic and chronic recurrent seizure phase of epilepsy rather than being associated with the acute damage in the wake of the initial epilepsy-precipitating injury in this model.

\section{Experimental procedures}

4.1. Seizure model

Animal experiments were carried out in accordance with the principals of the European Communities Council Directive (86/609/EEC) and were reviewed and approved by the Research Ethics Committee of the Royal College of Surgeons in Ireland, under license from the Department of Health, Dublin, Ireland. Procedures were undertaken as previously described (Engel et al., 2010a and Mouri et al., 2008). Briefly, adult male C57BL/ 6 mice (Harlan, UK) weighing 20-25 g ( $\mathrm{n}=96)$ were anesthetized using isoflurane (3-5\%) and maintained normothermic by means of a feedback-controlled heat blanket (Harvard Apparatus Ltd., Kent, England). Mice were then placed in a stereotaxic frame and three partial craniectomies performed to affix cortical skullmounted EEG electrodes (Bilaney Consultants Ltd., Sevenoaks, UK). EEG was recorded using a Grass Comet XL digital EEG (Medivent Ltd., Lucan, Ireland). A guide cannula was affixed (coordinates from Bregma: $\mathrm{AP}=-0.94 ; \mathrm{L}=-2.85 \mathrm{~mm}$ ) and the entire skull assembly fixed in place with dental cement. Anesthesia was discontinued and then mice were placed into a clear Perspex recording chamber which allowed free movement. After baseline EEG recordings, an injection cannula was lowered through the guide cannula for injection of KA (Ocean Produce International, Nova Scotia, Canada) into the basolateral amygdala nucleus $(0.3 \mu \mathrm{g}$ in $0.2 \mu \mathrm{l}$ phosphate-buffered saline, PBS). Nonseizure control mice received $0.2 \mu$ intra-amygdala vehicle (PBS) but were otherwise treated the same. 40 min following injection of KA or vehicle, mice received intraperitoneal lorazepam $(6 \mathrm{mg} / \mathrm{kg}$ ) to curtail seizures and reduce morbidity and mortality. Mice were euthanized after lorazepam at $4 \mathrm{~h}$ or $24 \mathrm{~h}$ (acute), 2 days (epileptogenesis period) and 14 days (epileptic) and perfused with saline to remove intravascular blood components. Brains were either flash-frozen whole in 2methylbutane at $-30^{\circ} \mathrm{C}$ and processed for histopathology or rapidly dissected on ice to obtain the hippocampus which was then stored at $-70^{\circ} \mathrm{C}$ until further use.

\subsection{Spontaneous seizure recording}

Long-term EEG recording to define the emergence of epilepsy was performed using implantable EEG telemetry units (Data Sciences International (DSI), St. Paul, MN, USA), as described previously (Engel et al., 2010a, Engel et al., 2010b and Engel et al., 2011). Mice underwent the same initial surgical procedure for affixing the injection cannula but were equipped with EEG transmitters (F20-EET, DSI) to record bilateral EEG from skull overlying the dorsal ipsilateral and contralateral hippocampi. EEG data were acquired using the Dataquest A.R.T. system (DSI). Following surgery, mice received intraamygdala KA, and then telemetry units were activated. Epileptic seizures were defined as high-frequency ( $>5 \mathrm{~Hz}$ ) high-amplitude ( $>2 \times$ baseline) polyspike discharges of $\geq 5 \mathrm{~s}$ duration (Jimenez-Mateos et al., 2008 and Mouri et al., 2008). Mice used for sterol measurements were not implanted with EEG telemetry units.

\subsection{Statin treatment}

Mice were pretreated with either lovastatin ( $4 \mathrm{mg} / \mathrm{kg}$, intra-peritoneal injection) or vehicle (20\% ethanol diluted in saline) for 3 days. On day 4 , mice underwent status 
epilepticus. Mice received the statin injections on day 4 both $1 \mathrm{~h}$ before and $1 \mathrm{~h}$ after KA injection. The lovastatin solution was prepared by dissolving pure lovastatin (Calbiochem, Merck) in 20\% ethanol and diluted to the final concentration with saline (pH 7.4). Fresh solutions were prepared daily. The mice continued daily injections of either statin or vehicle for a subsequent 3 day (i.e. total statin treatment 7 days). After euthanasia, the brains were removed and processed for histopathology. Digitized EEG recordings were analyzed offline using manual assessment as described before (Engel et al., 2010b). The occurrence of high amplitude high-frequency discharges (HAHFDs; $>5$ $\mathrm{Hz},>2 \times$ baseline discharges of $\geq 5 \mathrm{~s}$ duration) is synonymous with injury-causing electrographic seizures in the model. The duration of HAHFDs was determined by a reviewer in a blinded procedure.

\subsection{Histopathology}

For histopathology, brains were sectioned at $-20^{\circ} \mathrm{C}$ on a Leica cryostat and $12 \mu \mathrm{m}$ sections collected at the level of dorsal and ventral hippocampus $(-1.8 \mathrm{~mm}$ and $-2.9 \mathrm{~mm}$ from Bregma (Paxinos and Franklin, 2001)). Neurodegeneration was assessed using Fluoro-Jade B (FJB), as previously described (Engel et al., 2010a). Briefly, sections were air-dried and post-fixed in formalin followed by hydrating through graded alcohols. Sections were then rinsed in distilled water and transferred to $0.006 \%$ potassium permanganate solution for $15 \mathrm{~min}$. Sections were rinsed again and transferred to a $0.001 \%$ FJB solution according to manufacturer's recommendations (Chemicon Europe Ltd., Chandlers Ford, UK). After staining, sections were rinsed again, dried, cleared and mounted in DPX (Sigma-Aldrich). Hippocampal FJB positive counts were the average of two adjacent sections for the CA3 subfield under $40 \times$ lens magnification by an observer blinded to treatment conditions. For haematoxylin staining, sections were dehydrated through alcohols, cleared, rehydrated and then stained with hematoxylin (SigmaAldrich). After staining, sections were rinsed again, dried, cleared and mounted in DPX. For NeuN immunohistochemistry, sections were fixed and permeabilized, blocked in goat serum and incubated overnight with anti-NeuN antibodies (Millipore) followed by incubation with goat anti-rabbit IgG antibodies coupled to AlexaFluor 568 (BioSciences Limited, Dun Laoghaire, Ireland). Analysis of DNA damage was performed using a fluorescein-based TUNEL technique, according to manufacturer's instructions (Promega, Madison, WI, USA) (Engel et al., 2010a). Sections were mounted in medium containing 4, 6 diamidino-2-phenylindole (DAPI) (Vector Laboratories Ltd., Peterborough, UK) to visualize nuclei. Sections were examined using a Nikon 2000s epifluorescence microscope under Ex/Em wavelengths of 472/520 nm (green) and 540 to 580/600 to $660 \mathrm{~nm}$ (red) and images captured using a Hamamatsu Orca 285 camera.

\subsection{Sterol analysis}

For sterol analysis, the ipsilateral (site of major hippocampal pathology) and contralateral (non-lesioned side) hippocampus were dissected and stored at $-70{ }^{\circ} \mathrm{C}$ until they were processed. Hippocampi were weighed and homogenized in $1 \mathrm{ml}$ tris-buffered saline on ice. The homogenate was then added to $5 \mathrm{ml}$ Folch solution (chloroform:methanol 2:1) and $1 \mathrm{ml}$ saline with $1 \mathrm{mM}$ EDTA and butylated hydroxyl toluene. The mixture was vortexed before centrifugation at $500 \mathrm{~g}$ for $5 \mathrm{~min}$. The lower organic layer was collected in a new glass tube. The aqueous layer was re-extracted with $5 \mathrm{ml}$ chloroform and after centrifugation it was pooled with the organic phase collected from the first extraction. The lipid extracts were dried under a stream of argon and reconstituted in $6 \mathrm{ml}$ of folch and stored at $-20^{\circ} \mathrm{C}$. All the sterols were assayed by gas 
chromatography-mass spectrometry run in selective ion monitoring mode using deuterium labeled sterols as internal standards. To measure the total cholesterol concentration (esterified and unesterifed) lipid extract equivalent to $150 \mu \mathrm{g}$ of tissue was used in addition to 2000 ng of D6 labeled cholesterol. Sample processing included an alkaline hydrolysis step using potassium hydroxide, solid phase extraction using C18 columns and derivatisation with tetramethylsilane (TMS) (Bjorkhem et al., 1974). To measure the cholesterol precursors, lathosterol and desmosterol $2.5 \mathrm{mg}$ tissue was used along with $100 \mathrm{ng}$ d4 lathosterol (and $100 \mathrm{ng}$ d6 sitosterol) (Acimovic et al., 2009).

Alkaline hydrolysis was with sodium hydroxide followed by extraction with cyclohexane and derivatisation. To measure 24S- and 27-hydroxycholesterol, $2.5 \mathrm{mg}$ of tissue extract was used with $100 \mathrm{ng}$ d3 24 hydroxycholesterol and $25 \mathrm{ng}$ d5 27 hydroxycholesterol (Dzeletovic et al., 1995). Sample processing included an alkaline hydrolysis step using potassium hydroxide, followed by solid phase extraction using silica columns and derivatisation with TMS. The $\mathrm{m} / \mathrm{z}$ of the following ions were monitored:

cholesterol,458.4; [2H6]-cholesterol,464.4; lathosterol,458.4; desmosterol,343.3; [2H4]lathosterol,462.4; [2H6]-sitosterol,402.4; 24-hydroxycholesterol,413.4; [2H3]-24

hydroxycholesterol,416.4; 27-hydroxycholesterol,456.4 and [2H5]-27

hydroxycholesterol,461.4.

\subsection{Statistical analysis}

Data are presented as mean \pm SEM. For the sterol analysis, data was analyzed by ANOVA using GraphPad Instat followed by a Kruskal-Wallis post hoc test, comparing each KA group to its time-matched control. For histopathology and EEG analysis the Student's ttest was used. $\mathrm{P}<0.05$ was considered statistically significant.

Acknowledgments

This work was funded by a post-doctoral fellowship from the Irish Research Council for Science, Engineering and Technology (M.H.), the Health Research Board (PD/2009/31) and Science Foundation Ireland (08/IN.1./B1875). We would like to thank Anita Lövgren-Sandblom for her technical assistance and Ingemar Björkhem for his valuable comments on the manuscript. 
References

J. Acimovic, A. Lovgren-Sandblom, K. Monostory, D. Rozman, M. Golicnik, D. Lutjohann, I. Bjorkhem Combined gas chromatographic/mass spectrometric analysis of cholesterol precursors and plant sterols in cultured cells J. Chromatogr. B: Anal. Technol. Biomed. Life Sci., 877 (2009), pp. 2081-2086

D. Arabadzisz, K. Antal, F. Parpan, Z. Emri, J.M. Fritschy Epileptogenesis and chronic seizures in a mouse model of temporal lobe epilepsy are associated with distinct EEG patterns and selective neurochemical alterations in the contralateral hippocampus Exp. Neurol., 194 (2005), pp. 76-90

T. Araki, R.P. Simon, W. Taki, J.Q. Lan, D.C. Henshall Characterization of neuronal death induced by focally evoked limbic seizures in the C57BL/ 6 mouse J. Neurosci. Res., 69 (2002), pp. 614-621

I. Bjorkhem, R. Blomstrand, L. Svensson Serum cholesterol determination by mass fragmentography Clin. Chim. Acta, 54 (1974), pp. 185-193

I. Bjorkhem, T. Miettinen, E. Reihner, S. Ewerth, B. Angelin, K. Einarsson Correlation between serum levels of some cholesterol precursors and activity of HMG-CoA reductase in human liver J. Lipid Res., 28 (1987), pp. 1137-1143

I. Bjorkhem, D. Lutjohann, U. Diczfalusy, L. Stahle, G. Ahlborg, J. Wahren Cholesterol homeostasis in human brain: turnover of 24S-hydroxycholesterol and evidence for a cerebral origin of most of this oxysterol in the circulation J. Lipid Res., 39 (1998), pp. 1594-1600

I. Bjorkhem, S. Meaney Brain cholesterol: long secret life behind a barrier Arterioscler. Thromb. Vasc. Biol., 24 (2004), pp. 806-815

S. Dzeletovic, O. Breuer, E. Lund, U. Diczfalusy Determination of cholesterol oxidation products in human plasma by isotope dilution-mass spectrometry Anal. Biochem., 225 (1995), pp. 73-80

T. Engel, S. Hatazaki, K. Tanaka, J.H. Prehn, D.C. Henshall Deletion of puma protects hippocampal neurons in a model of severe status epilepticus Neuroscience, 168 (2010), pp. 443-450

T. Engel, K. Tanaka, E.M. Jimenez-Mateos, A. Caballero-Caballero, J.H. Prehn, D.C. Henshall Loss of p53 results in protracted electrographic seizures and development of an aggravated epileptic phenotype following status epilepticus Cell Death Dis., 1 (2010), p. e79

T. Engel, N. Plesnila, J.H. Prehn, D.C. Henshall In vivo contributions of BH3-only proteins to neuronal death following seizures, ischemia, and traumatic brain injury J. Cereb.

Blood Flow Metab., 31 (2011), pp. 1196-1210

S. Hatazaki, C. Bellver-Estelles, E.M. Jimenez-Mateos, R. Meller, C. Bonner, N. Murphy, S. Matsushima, W. Taki, J.H. Prehn, R.P. Simon, D.C. Henshall Microarray profile of seizure damage-refractory hippocampal CA3 in a mouse model of epileptic preconditioning Neuroscience, 150 (2007), pp. 467-477

X. He, A.M. Jenner, W.Y. Ong, A.A. Farooqui, S.C. Patel Lovastatin modulates increased cholesterol and oxysterol levels and has a neuroprotective effect on rat hippocampal neurons after kainate injury J. Neuropathol. Exp. Neurol., 65 (2006), pp. 652-663 M. Heverin, S. Meaney, D. Lutjohann, U. Diczfalusy, J. Wahren, I. Bjorkhem Crossing the barrier: net flux of 27-hydroxycholesterol into the human brain J. Lipid Res., 46 (2005), pp. 1047-1052

E.M. Jimenez-Mateos, S. Hatazaki, M.B. Johnson, C. Bellver-Estelles, G. Mouri, C. Bonner, J.H. Prehn, R. Meller, R.P. Simon, D.C. Henshall Hippocampal transcriptome after status epilepticus in mice rendered seizure damage-tolerant by epileptic preconditioning 
features suppressed calcium and neuronal excitability pathways Neurobiol. Dis., 32 (2008), pp. 442-453

H.J. Kempen, J.F. Glatz, J.A. Gevers Leuven, H.A. van der Voort, M.B. Katan Serum lathosterol concentration is an indicator of whole-body cholesterol synthesis in humans J. Lipid Res., 29 (1988), pp. 1149-1155

J.H. Kim, J. Jittiwat, W.Y. Ong, A.A. Farooqui, A.M. Jenner Changes in cholesterol biosynthetic and transport pathways after excitotoxicity J. Neurochem., 112 (2010), pp. 34-41

J.K. Lee, J.S. Won, A.K. Singh, I. Singh Statin inhibits kainic acid-induced seizure and associated inflammation and hippocampal cell death Neurosci. Lett., 440 (2008), pp. 260-264

Lund et al., 1999 E.G. Lund, J.M. Guileyardo, D.W. Russell cDNA cloning of cholesterol 24hydroxylase, a mediator of cholesterol homeostasis in the brain Proc. Natl. Acad. Sci. USA, 96 (1999), pp. 7238-7243

E.G. Lund, C. Xie, T. Kotti, S.D. Turley, J.M. Dietschy, D.W. Russell Knockout of the cholesterol 24-hydroxylase gene in mice reveals a brain-specific mechanism of cholesterol turnover J. Biol. Chem., 278 (2003), pp. 22980-22988

D.H. Mauch, K. Nagler, S. Schumacher, C. Goritz, E.C. Muller, A. Otto, F.W. Pfrieger CNS synaptogenesis promoted by glia-derived cholesterol Science, 294 (2001), pp. 1354-1357

Meaney, S., Heverin, M., Panzenboeck, U., Ekstrom, L., Axelsson, M., Andersson, U., Diczfalusy, U., Pikuleva, I., Wahren, J., Sattler, W., Bjorkhem, I., 2007. A novel route for the elimination of brain oxysterols: elimination of 27-hydroxycholesterol via conversion to 7alpha-hydroxy-3-oxo-4-cholestenoic acid. J. Lipid Res.

P. Montpied, F. de Bock, M. Lerner-Natoli, J. Bockaert, G. Rondouin Hippocampal alterations of apolipoprotein $\mathrm{E}$ and D mRNA levels in vivo and in vitro following kainate excitotoxicity Epilepsy Res., 35 (1999), pp. 135-146

G. Mouri, E. Jimenez-Mateos, T. Engel, M. Dunleavy, S. Hatazaki, A. Paucard, S.

Matsushima, W. Taki, D.C. Henshall Unilateral hippocampal CA3-predominant damage and short latency epileptogenesis after intra-amygdala microinjection of kainic acid in mice Brain Res., 1213 (2008), pp. 140-151

Y. Ohyama, S. Meaney, M. Heverin, L. Ekstrom, A. Brafman, M. Shafir, U. Andersson, M. Olin, G. Eggertsen, U. Diczfalusy, E. Feinstein, I. Bjorkhem Studies on the transcriptional regulation of cholesterol 24-hydroxylase (CYP46A1): marked insensitivity toward different regulatory axes J. Biol. Chem., 281 (2006), pp. 3810-3820

W.Y. Ong, E.W. Goh, X.R. Lu, A.A. Farooqui, S.C. Patel, B. Halliwell Increase in cholesterol and cholesterol oxidation products, and role of cholesterol oxidation products in kainate-induced neuronal injury Brain Pathol., 13 (2003), pp. 250-262

A Papassotiropoulos, D Lütjohann, M Bagli, S Locatelli, F Jessen, ML Rao, W Maier, I Björkhem, K von Bergmann, R. Heun Plasma 24S-hydroxycholesterol: a peripheral indicator of neuronal degeneration and potential state marker for Alzheimer's disease. NeuroRep., 11 (9) (2000), pp. 1959-1962

Paxinos, G., Franklin, K.B.J., 2001. The mouse brain in stereotaxic coordinates, second edition Elsevier, San Diego, CA. Pernot et al., 2011

F. Pernot, C. Heinrich, L. Barbier, A. Peinnequin, P. Carpentier, F. Dhote, V. Baille, C. Beaup, A. Depaulis, F. Dorandeu Inflammatory changes during epileptogenesis and spontaneous seizures in a mouse model of mesiotemporal lobe epilepsy Epilepsia, 52 (2011), pp. 2315-2325 
T.C. Piermartiri, S. Vandresen-Filho, B. de Araujo Herculano, W.C. Martins, D. Dal'agnolo, E. Stroeh, C.L. Carqueja, C.R. Boeck, C.I. Tasca Atorvastatin prevents hippocampal cell death due to quinolinic acid-induced seizures in mice by increasing Akt phosphorylation and glutamate uptake Neurotox. Res., 16 (2009), pp. 106-115

R.E. Pitas, J.K. Boyles, S.H. Lee, D. Foss, R.W. Mahley Astrocytes synthesize apolipoprotein E and metabolize apolipoprotein E-containing lipoproteins Biochim. Biophys. Acta, 917 (1987), pp. 148-161

R.E. Pitas, J.K. Boyles, S.H. Lee, D. Hui, K.H. Weisgraber Lipoproteins and their receptors in the central nervous system. Characterization of the lipoproteins in cerebrospinal fluid and identification of apolipoprotein B,E(LDL) receptors in the brain J. Biol. Chem., 262 (1987), pp. 14352-14360

D.M. Ramirez, S. Andersson, D.W. Russell Neuronal expression and subcellular localization of cholesterol 24-hydroxylase in the mouse brain J. Comp. Neurol., 507 (2008), pp. 1676-1693

P. Rangel, R.M. Cysneiros, R.M. Arida, M. de Albuquerque, D.B. Colugnati, C.A. Scorza, E.A. Cavalheiro, F.A. Scorza Lovastatin reduces neuronal cell death in hippocampal CA1 subfield after pilocarpine-induced status epilepticus: preliminary results Arq.

Neuropsiquiatr., 63 (2005), pp. 972-976

C. Thiele, M.J. Hannah, F. Fahrenholz, W.B. Huttner Cholesterol binds to synaptophysin and is required for biogenesis of synaptic vesicles Nat. Cell Biol., 2 (2000), pp. 42-49 C. Xie, J. Sun, W. Qiao, D. Lu, L. Wei, M. Na, Y. Song, X. Hou, Z. Lin Administration of simvastatin after kainic acid-induced status epilepticus restrains chronic temporal lobe epilepsy PLoS One, 6 (9) (2011), pp. 1-10,e24966 
Figure Legends

Fig. 1. Hippocampal neuropathology following intra-amygdala KA-induced status epilepticus in mice. (A) Photomicrograph of hippocampus stained with the neuronal marker NeuN showing main subfields. (B) Representative EEG recording showing high amplitude and high frequency spiking following KA-triggered seizures. (C) Representative photomicrograph of Fluoro-Jade B (FJB) stained hippocampus $24 \mathrm{~h}$ after KA-induced seizures. Note, FJB positive cells are mainly located in the CA3 subfield of the ipsilateral hippocampus (see arrow heads), whereas other subfields and contralateral hippocampus are spared. (D) Video still sequence of a spontaneous seizure that occurred 14 days after KA injection. (E) Representative EEG recording of a spontaneous seizure 14 days after KA injection. (F) Representative haematoxylinstained hippocampus of a mouse 14 days after KA injection. Arrows indicate the primary region of neuron loss. (G) Representative NeuN/TUNEL double immunostaining in mice 14 days after KA. Note the lack of TUNEL-positive cells in CA3 region suggesting the end of active neurodegeneration. Scale bars: $500 \mu \mathrm{m} \mathrm{A}, \mathrm{C}$ and F and $25 \mu \mathrm{m}$ in G. (CA1 and CA3=Cornu ammonis 1 and 3; DG=dentate gyrus).

Fig. 2. Lovastatin does not prevent seizure-induced neuronal death in mice. (A) Graph showing total seizure time in lovastatin-treated mice compared to vehicle-injected seizure animals. (B) Representative EEG traces from vehicle- and lovastatin-treated mice during status epilepticus induced by intra-amygdala KA. (C) Graph showing FJB cell counts and (right) representative photomicrograph of FJB-stained dorsal hippocampal sections $72 \mathrm{~h}$ after status epilepticus. (D) Graph showing FJB cell counts and (right) representative photomicrograph of FJB-stained ventral hippocampal sections $72 \mathrm{~h}$ after status epilepticus ( $\mathrm{n}=13$ per group). Scale bar: $20 \mu \mathrm{m}$.

Fig. 3. Sterol level changes in ipsilateral hippocampus after status epilepticus. Graphs show ipsilateral hippocampal levels of lathosterol (A), desmosterol (B), 24S hydroxycholesterol (C), 27 hydroxycholesterol (D) and cholesterol (E) at different time points after status epilepticus compared to non-seizure vehicle animals $(n=12$ per group at each time point). Absolute sterol concentrations per mg of wet tissue in control mice at $4 \mathrm{~h}$ : $28 \mathrm{ng}(\mathrm{A}), 110 \mathrm{ng}(\mathrm{B}), 46 \mathrm{ng}(\mathrm{C}), 0.2 \mathrm{ng}(\mathrm{D})$ and $15 \mu \mathrm{g}(\mathrm{E}) ; * \mathrm{P}<0.05 ; * * \mathrm{P}<0.01$; $* * * \mathrm{P}<0.001$.

Fig. 4. Sterol level changes in contralateral hippocampus after status epilepticus. Graphs show contralateral hippocampal levels of lathosterol (A), desmosterol (B), $24 \mathrm{~S}$ hydroxycholesterol (C), 27 hydroxycholesterol (D), and cholesterol (E) at different time points after status epilepticus compared to non-seizure vehicle animals $(n=12$ per group at each time-point). Absolute sterol concentrations per mg of wet tissue in control mice at $4 \mathrm{~h}$ : $30 \mathrm{ng}(\mathrm{A}), 120 \mathrm{ng}(\mathrm{B}), 45 \mathrm{ng}(\mathrm{C}), 0.13 \mathrm{ng}(\mathrm{D})$ and $15 \mu \mathrm{g}(\mathrm{E}), * \mathrm{P}<0.05 ; * * \mathrm{P}<0.01$; $* * * \mathrm{P}<0.001$. 
A

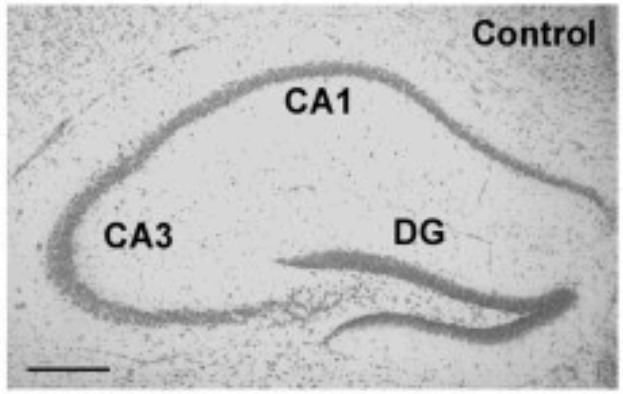

B

\section{KA-induced status epilepticus}

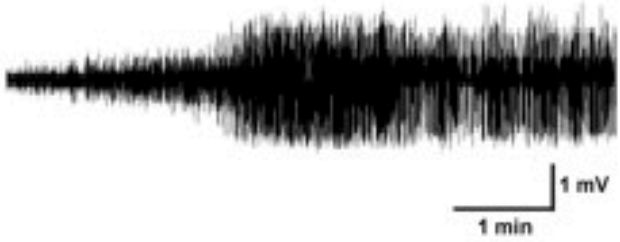

C

Status epilepticus (24h)
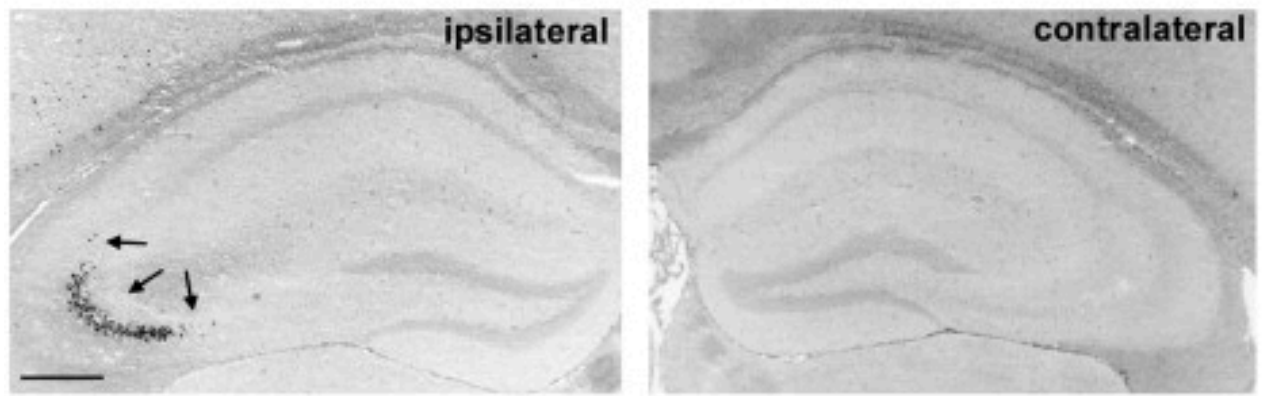

D

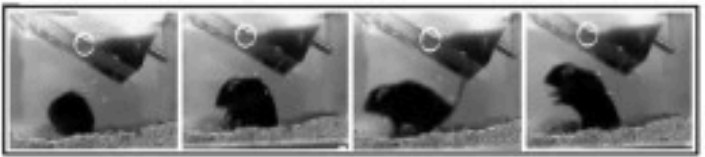

E

\section{Spontaneous seizure}

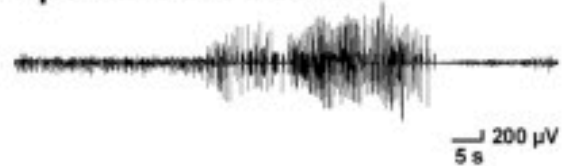

F

Epileptic (14 d)
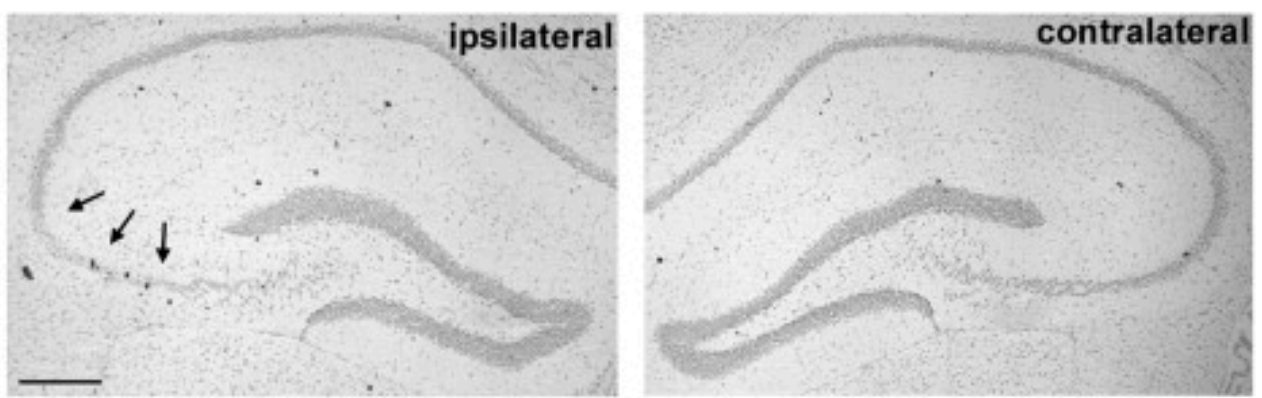

G

NeuN

TUNEL

Merge
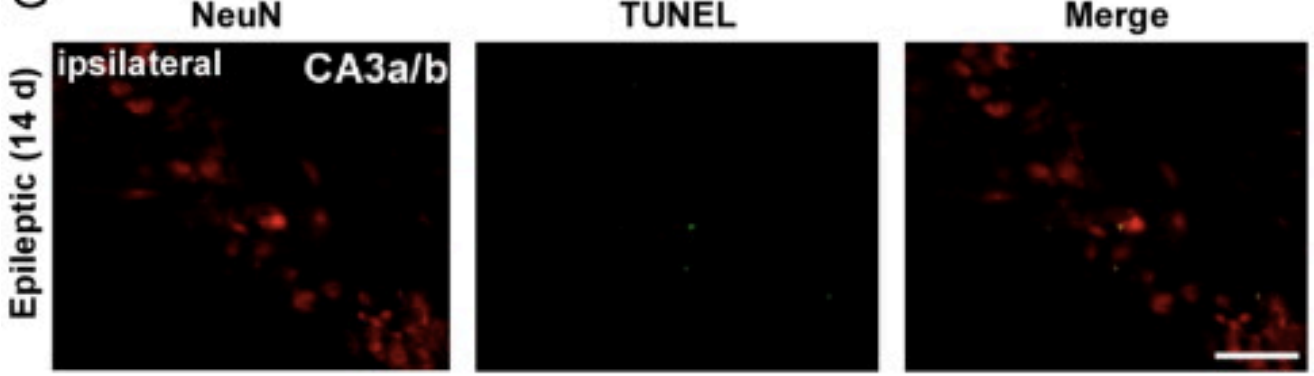

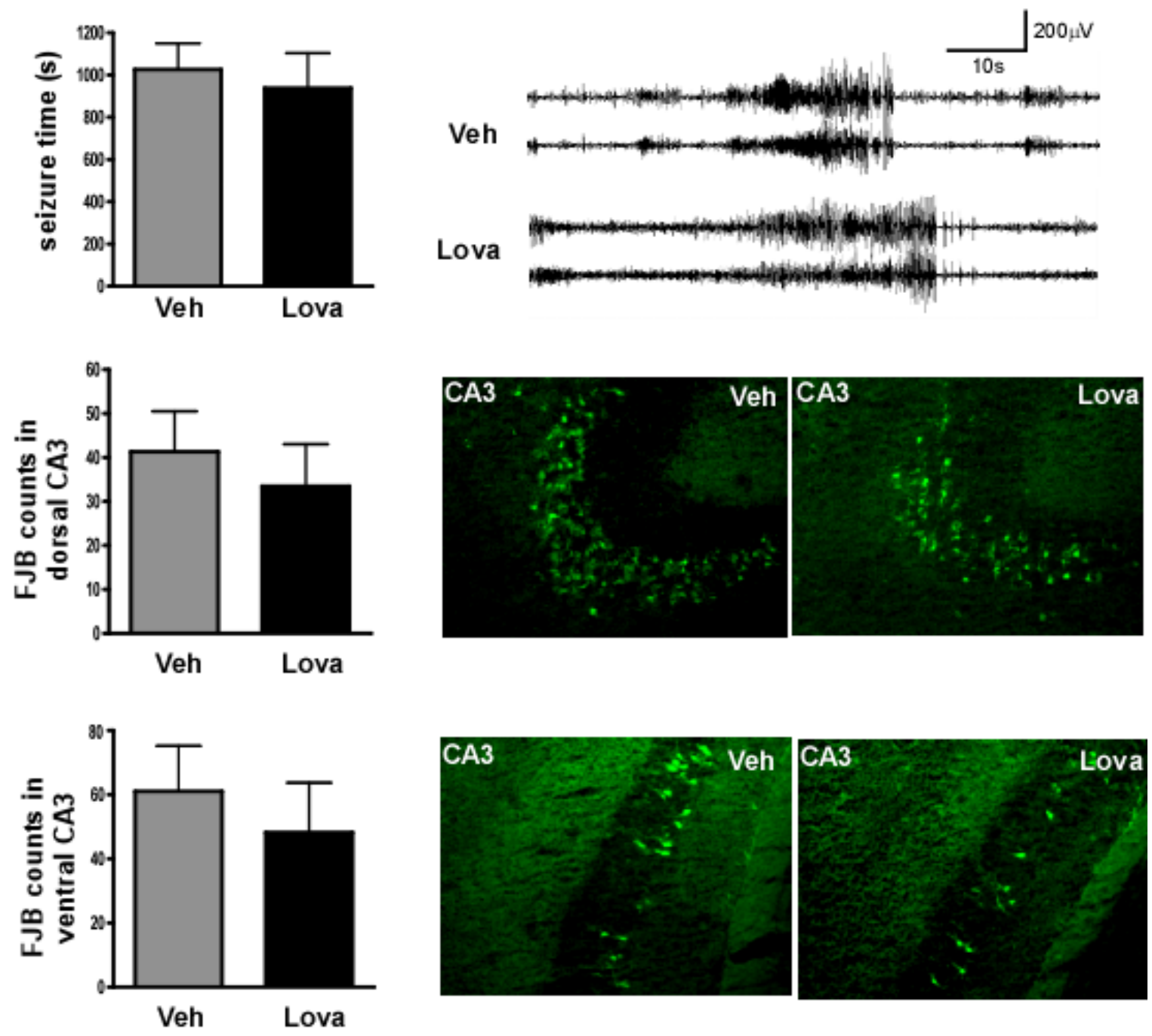

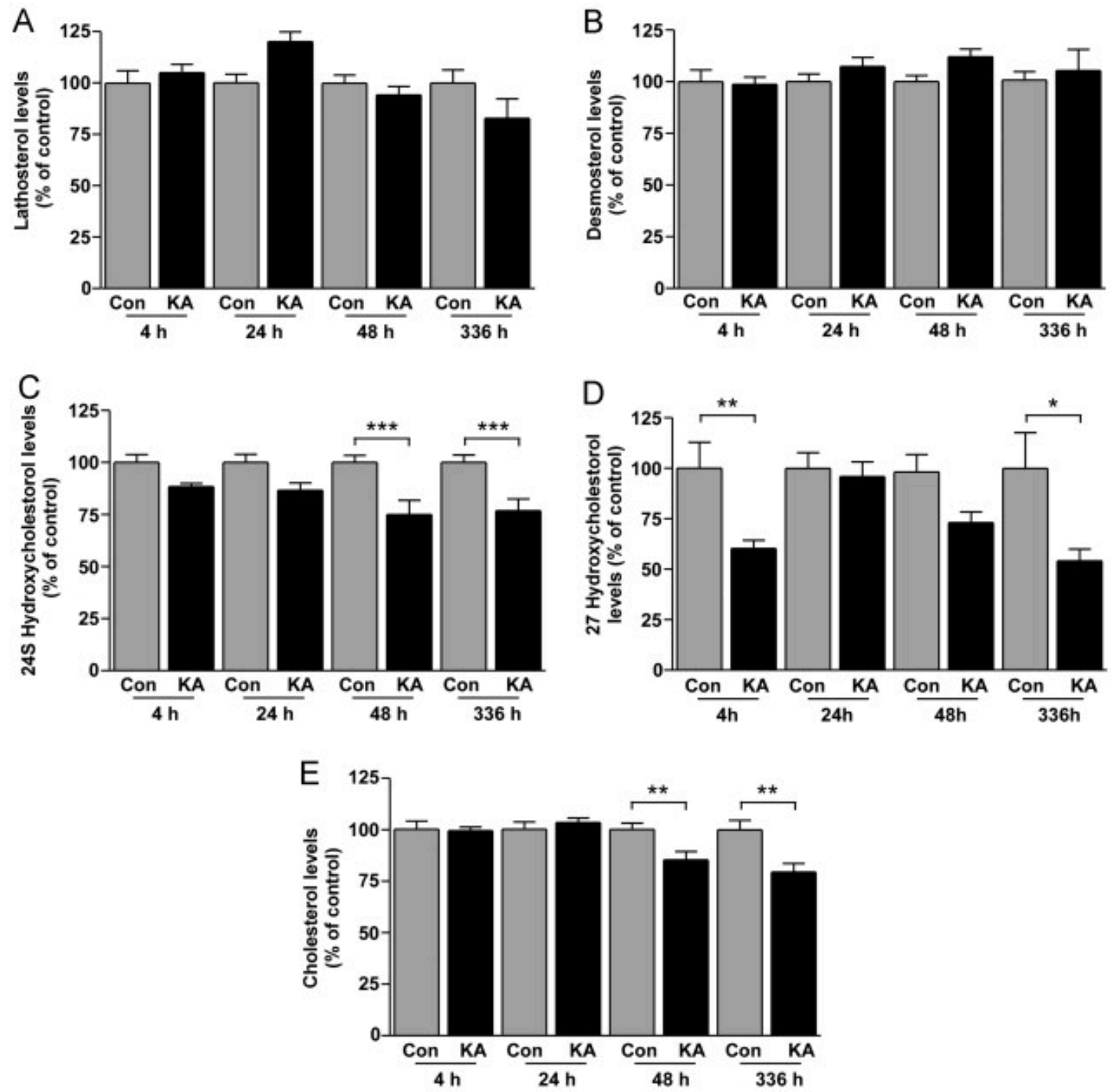

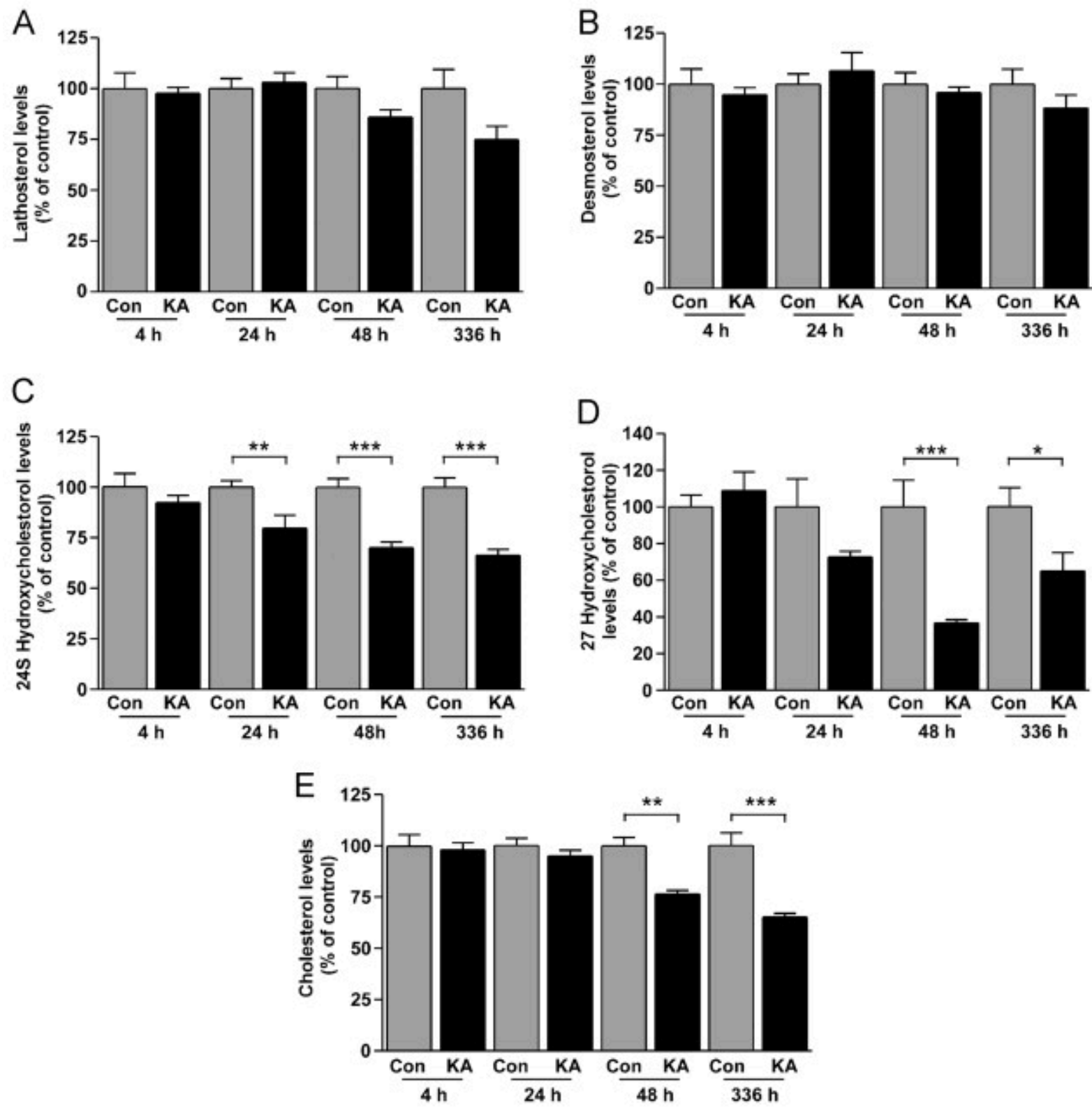